\title{
Electrical and Thermal System Considerations for MVDC Superconducting Distribution on Navy Ships
}

\author{
R.E. Hebner, A.L. Gattozzi, S.M. Strank, S.P. Pish, and J.D. Herbst \\ Center for Electromechanics \\ University of Texas, Austin, TX \\ r.hebner@cem.utexas.edu
}

\begin{abstract}
The interest in using a superconducting (SC) distribution grid on a ship designed with a medium voltage de (MVDC) system is a natural one, because superconductors (SCs) perform at their best under dc power. The potential advantages could be reduced losses, smaller cable plant size, and an electrically stiffer power bus. However, the use of SCs, does not eliminate losses completely and requires additional ancillary equipment. This paper provides an initial assessment of the potential benefits accrued from its adoption compared to any additional overhead, residual losses, and risk associated with a brand new shipboard system.
\end{abstract}

Keywords-Superconducting distribution; Superconducting cables; MVDC superconducting power.

\section{INTRODUCTION}

The US Navy is considering the use of superconducting components (SCs) in sections of the dc power distribution of a ship. The US Navy's recent reduction of the dc bus voltage for the new surface combatant, from the original $20 \mathrm{kV}$ to the new target of $12 \mathrm{kV}$, gives further incentive for the use of SCs since, for the same installed power capacity, the consequent increase in current levels favors systems with minimal resistive line losses.

Upon preliminary review, dc distribution would appear to be a natural fit as it would employ the SCs in their most favorable environment. The expectation is that this will result in a stiffer power bus, with fewer losses, and less volume and weight than the normal conductor counterpart [1-9]. Therefore, it is important to examine the implications of SCs in a ship's power distribution system, to quantify the anticipated benefits.

Recently, several pilot installations of high temperature superconducting (HTSC) cables have been undertaken in landbased systems [10-14]. The length of these installations, ranging from $30 \mathrm{~m}$ to $1,000 \mathrm{~m}$, are comparable to those expected on a Navy vessel, thus making the transition of this same technology to a ship seem rather straightforward. However, several distinctions between the two types of applications must be taken into consideration, in particular the following:

1. In the case of land utilities, it is often the primary objective to re-use existing right-of-ways and conduits in urban areas to accommodate more current capacity, and SCs are often the only viable option to facilitate the expanding load. The cost of upgrading the existing infrastructure can dwarf the cost of a SC installation. In the case of a ship, this benefit must be realized through a volume and weight reduction of the cable plant, including the additional accessories needed for the SC

This material is based upon research supported by, or in part by, the U.S Office of Naval Research under award number N00014-16-1-2956. system.

2. A secondary objective of land utilities implementing SC cabling is to lower their overall distribution voltage. The cost reduction derived from this may justify the cost of a SC system. A similar benefit may not be realized in a shipboard power system, where the range of practical voltages is much narrower.

3. A third motivation for land utilities is the reduction of loss in long transmission lines. In a ship, lengths between connection points are short and loss reduction with respect to normal conductors must be balanced against the additional complexity of a SC installation.

4. Another key difference to consider is that, whereas in land utilities the SC distribution tends to be point-to-point, in a ship the density of SC-normal transitions (number of taps per unit length) is much larger, as several connections will be necessary to support the zonal loads over the limited length of the distribution lines. This means that the SC-normal terminations will impose a much higher thermal load on the cooling system per unit distribution length than in a normal utility application. The implications of this must also be evaluated.

5. Finally, the load on a land SC transmission line is rather stable with slow diurnal cycles. In a ship, depending on circumstances, the load on a distribution cable section can vary abruptly. This generates transients that may impact the SC line performance. Furthermore, the much higher density of power converters in a ship will be a major source of harmonics. The additional losses on a SC distribution system due to fast timevarying sources must also be reviewed.

Therefore, it is imperative to closely examine the technical merits of using SCs on a MVDC ship power system and the extent to which the substitution of normal conductors should be carried out.

\section{PERFORMANCE ESTIMATE}

The Electric Ship Research and Development Consortium (ESRDC) has been developing a concurrent engineering design tool, known as S3D [15], for analyzing early designs of the new $10 \mathrm{kt}$ surface combatant on which the US Navy is considering to use SC distribution. Figure 1 reports the synthetic power distribution diagram of the baseline ship electrical system architecture (a split ring bus with four distribution zones) superimposed on the actual circuit schematic in the background. 


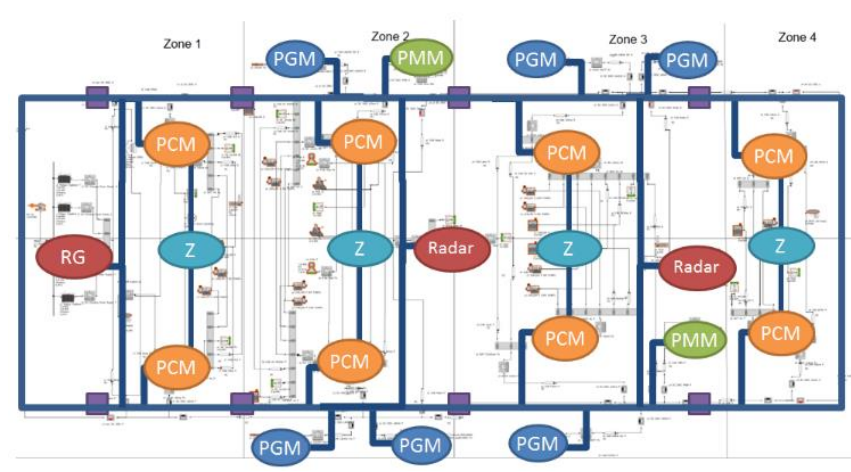

Fig. 1: Baseline Electrical Distribution System Diagram [15].

The top and bottom heavy horizontal lines are respectively the starboard and port main power buses that feed power to the four zones. These buses are rated for the largest current; thus, it makes sense to use them as test cases for the adoption of SC power cables. At the time the S3D design was done the final decision of $12 \mathrm{kV}$ for the system dc bus had not yet been made. Thus, the design assumed a bus voltage of $10 \mathrm{kV}$. From the S3D baseline design some information can be obtained about the definition of the main buses, which can be corrected for the new rating of the dc bus (Table I).

TABLE I: Main DC Bus Data from S3D Baseline Design [15]

\begin{tabular}{|c|c|c|}
\hline & S3D & New DC Bus \\
\hline Rated voltage of cable bundle, $\mathrm{kV}$ & 10 & 12 \\
\hline Rated current of cable bundle, $\mathrm{kA}$ & 10 & 8.3 \\
\hline Total bus length, $\mathrm{m}$ & 138 & 138 \\
\hline Number of cable bundle sections & 3 & 3 \\
\hline Average cable bundle length, $\mathrm{m}$ & 46 & 46 \\
\hline OD of each cable, mm & 57.9 & 57.9 \\
\hline Number of cables per bundle & 6 & 5 \\
\hline Resistance per unit length, $\mathrm{m} \Omega / \mathrm{m}$ & 0.030 & 0.036 \\
\hline Weight per unit length, kg/m & 50.8 & 42.3 \\
\hline Number of connections to dc bus & 11 & 11 \\
\hline
\end{tabular}

If one of the dc buses were running at full capacity for its whole length, the power loss in one of its sections would be given by:

$$
P_{C U}=r l \cdot l^{2}=0.036 \cdot 10^{-9} \cdot 46 \cdot 8300^{2}=114 \mathrm{~kW}(1)
$$

where

$$
\begin{aligned}
& r=\text { Resistance per unit length, } \Omega / \mathrm{m} \\
& l=\text { Section length, } \mathrm{m} \\
& I=\text { DC bus current, A }
\end{aligned}
$$

However, we must consider the average power loss over a realistic mission profile for the ship, since the ship would not be running at maximum capacity at all times, even leaving aside any consideration of a reasonable operating margin above the maximum expected. Again, we can take data from the S3D design exercise to derive the average power utilization factor for a ship. The summary of the results are reported in Table II.

TABLE II: Typical Mission Profile and Power Utilization from the S3D Baseline Design [15]

\begin{tabular}{|c|c|c|}
\hline Mission Segment & Days & $\begin{array}{c}\text { Electrical } \\
\text { Power, MW }\end{array}$ \\
\hline Peacetime Cruise & 90 & 23.0 \\
\hline Sprint to Station & 1 & 43.5 \\
\hline On Station & 7 & 23.7 \\
\hline
\end{tabular}

From these figures, we derive that, whereas the installed rated power of the ship is $100 \mathrm{MW}$, the average power used over a typical mission is given by

$$
\bar{P}=\frac{\sum_{1}^{3} d_{i} P_{i}}{\Sigma_{1}^{3} d_{i}}=23.3 M W
$$

where

$$
\begin{aligned}
& d_{i}=\text { number of days in the } \mathrm{i} \text {-th mission segment } \\
& P_{i}=\text { electrical power used in the i-th mission segment }
\end{aligned}
$$

Thus we have, for a constant bus voltage of $12 \mathrm{kV}$, a current utilization factor $u$ equal to 0.233 leading to an average current of $u I=1,942 \mathrm{~A}$ instead of the rated 8,300 A, and a Joule loss in the bus section considered of $6.24 \mathrm{~kW}$ instead of $114 \mathrm{~kW}$ as calculated in (1).

By comparison, let us examine the loss in the same section if the main bus were realized using SC cables. The section most heavily loaded with normal-SC interfaces is that in zone 2 where four interfaces are distributed throughout the zone with rated currents of $3.55 \mathrm{kA}, 0.92 \mathrm{kA}, 0.35 \mathrm{kA}$, and $4 \mathrm{kA}$. The heat input at these tap points is estimated to be $50 \mathrm{~W} / \mathrm{kA}$ for each tap point [16]. Thus, the power input to the cryogenic system at the normal-SC interfaces is $50 \times(3.55+0.92+0.35$ $+4)=441 \mathrm{~W}$. Furthermore, the heat input along the length of the cable is estimated to be $1 \mathrm{~W} / \mathrm{m}$ [17], resulting in an additional heat load of $1 \times 46=46 \mathrm{~W}$. Notice that, in this case, these heat loads are independent of the actual current carried in the conductor or in the joints, since the heat loads are only dependent on the geometry and construction details of the system: the same heat loads would be present even if no currents were carried in the SC system.

Therefore, the total power input due to heat exchange between the SC and the surroundings is $0.487 \mathrm{~kW}$. This heat will have to be removed by the cooling system, which must keep the SC below $77^{\circ} \mathrm{K}$. At this temperature, the effective multiplier converting each Watt of power input to power required by the cryogenic system is approximately 20 . In 
summary, the equivalent loss of the SC system would be $20 \mathrm{x}$ $0.487=9.74 \mathrm{~kW}$, which is actually higher than the loss in the system with normal conductors averaged over a mission profile $(6.24 \mathrm{~kW})$.

This approach, exemplified in a specific case, can be generalized as described below. The total power loss in the normal conductor system is given by

$$
P_{N}=P_{C u}\left(1+k_{\mathbb{N}}\right)=r l \cdot(u I)^{2}\left(1+k_{\mathbb{N}}\right)
$$

where we have considered also the additional air conditioning power needed to keep the ambient temperature constant due to Joule loss, considered here proportional to this same loss via the factor $k_{N}$.

Also, if we let

$p_{\text {Bus }}=$ heat load per unit length into the body of the SC section

$p_{\text {Tap }}=$ heat load per unit current at a normal-SC interface joint N)

$I_{\text {Tap n }}=$ current rating of the nth normal-SC joint (total of

$k_{S C}=$ power required by the cooling system for each Watt of heat exchanged with the environment

$P_{S C}=$ total power loss in the SC system

then

$$
P_{S C}=k_{S C}\left(p_{\text {bus }} l+\sum_{1}^{N} p_{\text {Tap }} I_{\text {Tap } n}\right)=k_{S C}\left(p_{\text {bus }} l+p_{\text {Tap }} I_{T}\right)
$$

where $I_{T}$ is the sum total of all normal-SC rated tap currents in the section considered. The SC system becomes preferable to the normal system when

$$
\begin{gathered}
P_{N}>P_{S C} \\
r l \cdot(u I)^{2}\left(1+k_{N}\right)>k_{S C}\left(p_{\text {Bus }} l+p_{\text {Tap }} I_{T}\right) \\
l>\frac{k_{S C} p_{T a p} I_{T}}{r(u I)^{2}\left(1+k_{N}\right)-k_{S C} p_{\text {sus }}}
\end{gathered}
$$

Substituting the parameter values listed previously, this leads to the condition that, for our section of bus, SCs would be preferable to $\mathrm{Cu}$ conductors if the bus length is at least 65 $\mathrm{m}$ long, which, as expected, is larger than the $46 \mathrm{~m}$ of the actual bus section.

At this point, it is also worth mentioning that we have ignored, in the analysis above, the fact that the section of power bus under consideration is terminated at both ends into two dc interrupters. These interrupters will be realized with normal conductors and have not been included in the calculations. This would have penalized the SC system even more and, in fact, points to the need of developing an opportune SC interrupter.

Finally, it should be pointed out that the ESRDC S3D working group has adopted a different architecture than the baseline design of Figure 1 for the analysis of a ship with HTSCs. This new zonal topology was developed loosely based on a proposed MVDC architecture circulated by the U.S. Navy [18]. The new topology essentially groups together the normal-SC interfaces at the end of the bus section into a large integrated bus node rather than intersperse them throughout the section (Figure 2). Therefore, the previous analysis still holds practically unchanged.

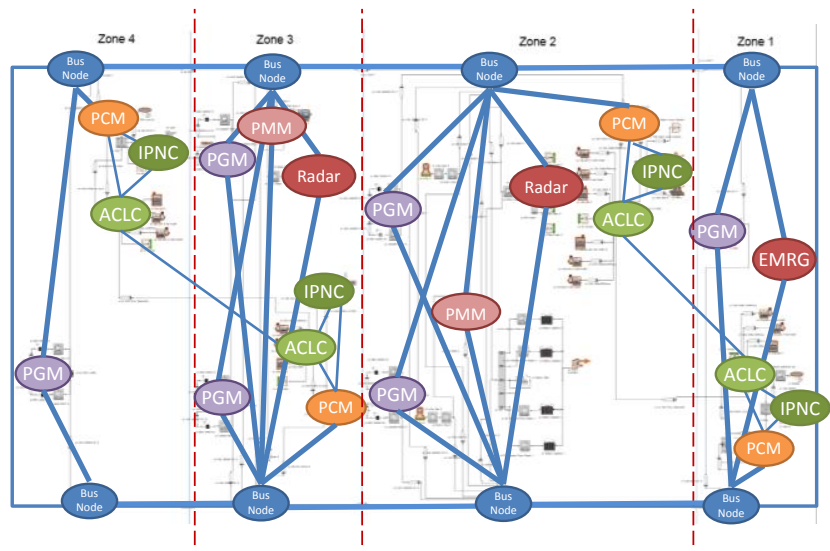

Fig. 2: Alternative Topology Distribution Scheme [15].

The analysis up to this point has been conducted with the focus on the efficiency of the system. Another viewpoint is the consideration of the system size. The normal conducting system for the bus section under consideration can be realized with 6 copper $(\mathrm{Cu})$ bus-bars of cross sectional size 1/4"x6", allowing a $30{ }^{\circ} \mathrm{C}$ rise over an ambient of $40{ }^{\circ} \mathrm{C}$ [19]. For a 46 $\mathrm{m}$ long section and two buses of opposite polarity, this translates into a total bus system weighing $4,769 \mathrm{~kg}$.

It is difficult to estimate the weight of the equivalent $\mathrm{SC}$ system without a detailed design. Weight reductions of $50 \%$ and up to $90 \%$ have been reported in the literature for systems of somewhat comparable specifications including both conductors and cryogenic apparatus. Thus, in our case, in the best hypothesis, the SC system would be weighing $477 \mathrm{~kg}$ with a weight savings of 4,292 kg. Approximately $25 \%$ of the system weight could be assigned to the cable cryostat (120 $\mathrm{kg}), 20 \%$ to the current leads $(95 \mathrm{~kg})$ and the rest $(262 \mathrm{~kg})$ to the cryo-cooler and supporting equipment [20].

Again generalizing these results, if we let

$d_{C u}=$ weight per unit length of the $\mathrm{Cu}$ bus bar system

$d_{S C}=$ weight per unit length of the SC cable

$d_{c s}=$ weight per unit length of the cryostat

$W_{c c}=$ total weight of cryo-cooler 
and if we assume that the weight of the cryo-cooler system is the sum of a fixed section $W_{c c o}$ and of a variable portion proportional to cable length as follows

$$
W_{c o}=W_{c c o}+\alpha l
$$

then the SC system is preferable when the normal system weight is larger, namely

$$
d_{c u} l>d_{s c} l+d_{c s} l+W_{c c o}+\alpha l
$$

This leads to the following condition

$$
l>\frac{W_{c c p}}{d_{c u}-\left(d_{s c}+d_{c c^{+}}+\alpha\right)}
$$

Impressive as the weight-saving enabled by SCs is, it is, however, achieved comparing a SC system with a $\mathrm{Cu}$ system that includes no provisions for improving its performance. For example, some forced cooling may be added to the $\mathrm{Cu}$ conductors: with a suitable cooling system, the $\mathrm{Cu}$ conductor temperature could be kept at $-85{ }^{\circ} \mathrm{C}$ (still well above the -200 ${ }^{\circ} \mathrm{C}$ needed for the SC system) instead of letting it rise to its rated value of $70{ }^{\circ} \mathrm{C}$, thus halving its resistivity and Joule losses. Equivalently, at this lower operating temperature the conduction losses could be kept the same, but the $\mathrm{Cu}$ cross section and weight could be reduced by $50 \%$.

Likewise, Aluminum (Al) conductors, opportunely treated, could be considered instead of $\mathrm{Cu}$ for the normal distribution system. Although $\mathrm{Al}$ has a resistivity which is $67 \%$ higher than $\mathrm{Cu}$, its density is $30 \%$ that of $\mathrm{Cu}$, thus allowing trading off some conduction losses (we saw previously that normal conducting systems fair actually better than SC in the case of our ship section) for some weight reduction. Of course, the same comments made for the case of $\mathrm{Cu}$ regarding the opportunity to cool the conductors below their normal operating temperature apply to $\mathrm{Al}$ as well, further reducing the weight advantage of a SC system. Although the use of $\mathrm{Al}$ on ships has not been considered because of other serious problems, like corrosion and mechanical issues, by the same token nobody would have ever dreamt of using ceramic-like materials like today's HTSCs as conductors aboard a ship only a few decades ago. It is at least conceivable that the natural properties that make Al unsuitable may be corrected with an R\&D effort similar to that employed in the case of HTSCs.

What should be kept in mind is that conventional systems continue to improve, although less dramatically than new technology, but still in our case, establishing a moving target for superconducting cables. Recent results, for example, seem to indicate that conventional ac cables perform much better under dc power, at least from the standpoint of partial discharge inception voltage [21]. On the basis of these results it could be possible to reduce the size of insulation required on a cable for dc ship service from that dictated by conventional standards, thus improving the weight and volume of electrical systems based on normal conductors. Furthermore, advances in dielectric materials based on nano-technology also point to the possibility of reducing the required insulation thickness in an otherwise normal cable [22].

In conclusion, there seem to be good opportunities for normal conducting systems to be made at least competitive with SC systems from the standpoint of efficiency and weight and still retain the advantages of a well proven simpler technology.

\section{RELIABILITY, MAINTENANCE, AND COST}

It is well known that the reliability of a complex system depends heavily on the number and variety of components and subsystems. The introduction of SCs on a ship power system will entail several new subsystems all of critical importance for the proper functioning of the ship, which are not needed in a normal conductor power system: e.g., cryo-coolers, cryostats, special fluids, special transition joints, probably also a vacuum system, etc. All these systems will have to be qualified for marine duty and obviously will impact the reliability of the whole system. A complete study of the failure modes and effects, of the survivability of the system, and of the mean time between failures and to recovery must be conducted in order to qualify SCs for use on a warship.

There are also practical questions on the impact on maintenance schedules and spare parts. Ultimately, also the impact on cost must be considered, as the industry of HTSCs is not yet developed enough to be able to make available standard parts as commercial off the shelf (COTS) components benefiting from an economy of scale. At the present time, all these studies must still be conducted in the necessary details [23].

\section{USE OF SUPERCONDUCTORS ABOARD NAVY SHIPS}

To date, SC technology has been installed on one Navy ship: the DDG76 destroyer has a SC degaussing system which has been performing well [24]. Within the context of our analysis reported above, the degaussing system is an excellent candidate for HTSCs, since it is a self-contained SC system with a minimal number of normal-SC interfaces, and one where the cable length is quite long. Both these factors, as we have seen, play in favor of a SC system.

Another system which is a natural application for SCs is the SC magnetic energy storage system (SMES), since it shares the same characteristics of the degaussing system of long cable length and of being rather segregated from the rest of the normal conductors. Furthermore, a SMES can only be realized with SCs, since the need for zero resistance is paramount for its functioning. A drawback of a SMES system, however, is the size. For fundamental reasons related to magnetic shielding [25], batteries, flywheels, and fuel cells have energy density that is a factor of 5 to 10 higher than an SMES unit.

Rotating machines are also good candidates for SC technology, despite the additional complexity in some cases of refrigerating a rotating mass. Like the degaussing and SMES systems, rotating machines have long cable runs with few interfaces with normal contacts. In addition, they enjoy a favorable aspect ratio, as the SC surface to volume ratio is small. Additionally, they maximize the benefit of SCs since they tend to handle a large fraction of (e.g. propulsion motors), if not all (e.g. generators), the ship electrical power. Not surprisingly, rotating machines were the first to be targeted for SC applications [26]. Later work has shown, 
however, that it is more difficult to make a superconducting rotating machine than a conventional one for power levels below $5 \mathrm{MW}$ [27]. The promise of smaller size is driven by the expectation that it is possible to achieve an air gap magnetic field greater than the approximately $1 \mathrm{~T}$ field achievable in conventional machines [28]. This has proven to be a significant design challenge, especially for smaller machines.

The preponderance of superconducting rotating machines use the air gap as the break between the cryogenic portion of the circuit and the room temperature portion. It should also be noted that both superconducting and room temperature rotating machines can be made in either wound field or "permanent magnet" topologies. In superconducting machines wound field demonstrations have dominated even though depositing YBCO on a substrate that can be bent into the appropriate geometries has proven to be a challenge. However, YBCO can also be made into a ceramic puck that resembles a permanent magnet. When exposed to a magnetic field, this material will produce what is called a "trapped field magnet", which is the functional equivalent of a permanent magnetic. This type of superconducting rotating machine has been built and demonstrated [29].

Also, here are at least two other possible topologies for superconducting rotating machines. One is to provide thermal insulation for the superconducting winding so that the remainder of the rotor can operate at room temperature. The other is to operate the rotor and the stator at cryogenic temperature. This, however, would require a much more extensive cryogenic system for success.

One way to expedite the adoption of SCs in the power distribution of a Navy vessel is the further reduction of the dc bus voltage from the present target of $12 \mathrm{kV}$. This will force higher current levels in the conductors and, thus, will be an advantage for a system that can function with no conduction losses. The problem of reducing too much the bus voltage, however, is that it may require complex infrastructure changes in all other components, as one shifts from a voltage dominated system to a current dominated one. For example, all protective devices and schemes may have to be redesigned, new semiconductor switches may have to be developed, power converter architectures may have to be changed, the control schemes may have to be reformulated, etc.

The long term prospects of using SCs for the electrical power distribution system are good, despite the residual challenges still present [30]. It must be noted that much depends on progress in technology that does not involve the physics of SCs per se, like better refrigeration systems, better thermal rejection, and better normal-SC terminations. For example, the usual refrigeration system based on liquid Nitrogen is not acceptable on a ship because of asphyxiation hazards, thus a system based on Helium gas has been proposed [31-32]. Of course, any new development in the area of SC materials proper will be welcome, and the field has demonstrated repeatedly the ability to make quantum leaps forward. However, this revolutionary more than evolutionary progress cannot be anticipated. Thus, it will be advances in conventional technology that will make the adoption of SCs on ships more appealing and possibly compelling when compared with normal conductors. At the present time, though, it does seem that a persuasive case for the use of SCs for power distribution on a ship is still in the future.

\section{CONCLUSIONS}

Some macroscopic issues related to the adoption of SCs on a Navy ship have been considered. A basic analysis has been performed from an efficiency and a weight saving viewpoints. The results indicate that for a destroyer class ship installation of SC power cables does not lead to efficiency improvements even when compared to basic $\mathrm{Cu}$ conductors operating at rated temperature. SCs do provide definite weight reductions when compared to normal conductors, although these advantages are not as large as initially projected if a suitable amount of forced cooling is implemented for the normal conductors. Questions regarding reliability, maintainability, and cost continue to remain on the agenda before adoption of SCs can seriously be considered beyond some specific well defined applications like degaussing systems.

The inherent potential advantages of superconductivity in ship power systems have stimulated significant research investment in rotating machines, cables, and SMES for decades. In addition, the widespread availability of superconducting magnets stimulated the development of magnetic resonance imaging (MRI). So, the technology is commercial.

Power system applications, however, are rare for reasons like those highlighted in this analysis. If one were to design a ship power system today that was small, light, reliable, and affordable, one would not include superconducting components in the power systems. With significant additional research, the answer may well be different in the future.

\section{REFERENCES}

[1] J.V. Minervini, L. Bromberg, P. Michael, C. Miles, N.R. LaBounty: Superconducting DC power transmission and distribution, MIT Plasma Science and Fusion Center, Feb. 18, 2009

[2] M. Noe, R. Bach, W. Prusseit, D. Willen, W. Goldacker, J. Poelchau, C. Linke: Conceptual study of superconducting urban area power systems, IEEE/CSC \& ESAS Europ. Supercon. News Forum (ESNF), no. 11, pp. 1-8, Jan. 2010

[3] J. McCall, B. Gamble, S. Eckroad: Combining superconductor cables and VSC HVDC terminals for long distance transmission, IEEE Conf. Innov. Technol. Effic. Reliable Elec. Supply (CITRES), pp. 47-54, Sept. 27-29, 2010

[4] S.S. Kalsi: Applications of High Temperature Superconductors to Electric Power Equipment, IEEE Press 2011

[5] G-J Lee: Superconductivity application in power system, Chapter 3 in "Applications of High-Tc Superconductivity", A. Luiz Ed., Intech, June 27, 2011

[6] C. Rey, Ed.: Superconductors in the Power Grid: Materials and Applications, Elsevier 2015 
[7] A. Morandi: HTS DC Transmission and Distribution: Concepts, Applications and Benefits, Supercond. Sci. Technol., no. 28, pp. $1-6,2015$

[8] H. Thomas, A. Marian, A. Chervyakov, S. Stuckrad, D. Salmieri, C. Rubbia: Superconducting Transmission Lines: Sustainable Electric Energy Transfer with Higher Public Acceptance?, Renew. and Sustain. Energy Rev., no. 55, pp. 5972,2016

[9] B.G. Marchionini, Y. Yamada, L. Martini, H. Ohsaki: HighTemperature Superconductivity: A Roadmap for Electric Power Sector Applications, 2015-2030, IEEE Trans. Appl. Supercon., vol. 27, no. 4, June 2017

[10] SuperPower: "SuperPower successfully concludes Albany HTS Cable Project" , Jan. 2008 http://www.superpowerinc.com/content/superpower-successfully-concludes-albany-htscable-project-demonstrating-world\%E2\%80\%99s-first-integ

[11] M. Heger: Superconductors Enter Commercial Utility Service, $\begin{array}{llll}\text { IEEE Spectrum, July } & 2008\end{array}$ http://spectrum.ieee.org/energy/the-smarter-

grid/superconductors-enter-commercial-utility-service

[12] "First Superconductor Cable Energized in Korea's Power Grid", T\&D World, Oct. 5, 2011 http://tdworld.com/overheaddistribution/first-superconductor-cable-energized-korea-spower-grid

[13] S. Patel: High-Temperature Superconductor Technology Stepped Up, Power, March 1, 2012 http://www.powermag.com/high-temperature-superconductortechnology-stepped-up/

[14] M. Landgraf: Operation of Longest Superconducting Cable Worldwide Started, May 12, 2014 https://phys.org/news/201405-longest-superconducting-cable-worldwide.html

[15] R. Smart, J. Chalfant, J. Herbst, B. Langland, A. Card, R. Leonard, A. Gattozzi, "Using S3D to Analyze Ship System Alternatives for a 100 MW 10,000 ton Surface Combatant," ESRDC Report, April 2017

[16] C.N. Rasmussen, C. Rasmussen: Optimization of termination for a high-temperature superconducting cable with a room temperature dielectric design, IEEE Trans. Appl. Supercon., vol. 9, no. 1, pp. 45-49, March 1999

[17] K. Ueda, O. Tsukamoto, S. Nagaya, H. Kimura, S. Akita: R\&D of a $500 \mathrm{~m}$ superconducting cable in Japan, IEEE Trans. Appl. Supercon., vol. 13, no. 2, pp. 1946-1951, June 2003

[18] N. Doerry, J. Amy: "Design Considerations for a Reference MVDC Power System", SNAME Maritime Conv., Nov. 1-5, 2016.

[19] Copper Development Assoc., Inc.: https://www.copper.org/applications/electrical/busbar/busbar_a mpacities.html

[20] P.C. Michael, L. Bromberg, A.J. Dietz, K.J. Cragin, C. Gold: Design and Test of a Prototype $20 \mathrm{kA}$ HTS DC Power Transmission Cable, IEEE Trans. Appl. Supercon., vol. 25, no. 3, June 2015

[21] X. Feng, R. Hebner, A. Gattozzi, and S. Strank: "Evaluation of DC Power Cables to Reduce Weight/Volume Impact on Future Navy Platforms Phase II", Progress Report on ONR Contract: N00014-16-1-3166 to The University of Texas Center for Electromechanics, June 2017
[22] X. Feng, R. Hebner, A. Gattozzi: "Evaluation of Potential for Nano-enhanced Dielectrics to Enable High Power Density Medium Voltage DC Cables", IEEE Electrical Insulation Conference, June 11-14, 2017

[23] P. Haldar, P. Abetti: Absolute Zero, as the Name Suggests, is as Cold as it Gets, IEEE Spectrum, vol. 48, no. 3, March 2011

[24] J.T. Kephart, B.K. Fitzpatrick, P. Ferrara, M. Pyryt, J. Pienkos, E.M. Golda: High Temperature Superconducting Degaussing from Feasibility Study to Fleet Adoption, IEEE Trans. Appl. Supercon., vol. 21, no. 3, pp. 2229-2232, June 2011

[25] K.R. Davey, R.E. Hebner. "A fundamental look at energy storage focusing primarily on flywheels and superconducting energy storage." CEM Publications (2003). https://repositories.lib.utexas.edu/bitstream/handle/2152/33085/ PN_280_Davey.pdf?sequence $=1 \&$ isAllowed $=y$

[26] A.D. Appleton: Development of Superconducting DC Machines at International Research \& Development Co., Ltd., Proc. IEEE, vol. 61, no. 1, pp. 106-111, Jan. 1973

[27] K.R. Davey, et al. "High speed generator trade study." CEM Publications (2006). https://repositories.lib.utexas.edu/bitstream/handle/2152/33105/ PN_306_Davey.pdf?sequence $=1$ \&isAllowed=y

[28] G. Snitchler, B. Gamble,, S.S.. Kalsi. "The performance of a 5 MW high temperature superconductor ship propulsion motor." IEEE Transactions on Applied Superconductivity 15.2 (2005): 2206-2209.

[29] X. Feng, et al. "Radial flux high temperature superconductor motor using bulk trapped field magnets." Electric Machines and Drives Conference, 2009. IEMDC'09. IEEE International. IEEE, 2009.

[30] J. Miller, D. Santosusso, M. Uva, B. Fitzpatrick: Naval Superconducting Integrated Power System (SIPS), Proc. ASNE Intell. Ship Symp., pp. 1-8, 2013

[31] J.A. Souza, J.C. Ordonez, R. Hovsapian, J.V.C. Vargas: Thermal Modeling of Helium Cooled High-Temperature Superconducting DC Transmission Cable, IEEE Trans. Appl. Supercon., vol. 21, no. 3, pp. 947-952, June 2011

[32] P. Cheetham, J. Viquez, L. Graber, C.H. Kim, H. Rodrigo, S. Pamidi: Novel Design Concept and Demonstration of a Superconducting Gas-Insulated Transmission Line, IEEE Trans. Appl. Supercon., vol. 27, no. 4, June 2017 